\title{
GEN - Grupo de Estudos Nietzsche 25 anos
}

Scarlett Marton

Resumo: trata-se de fazer um balanço, ainda que parcial, da atuação do GEN - Grupo de Estudos Nietzsche tanto no Brasil quanto no exterior nos seus vinte e cinco anos de existência.

Palavras-chave: GEN - Cadernos Nietzsche - Encontros Nietzsche - Coleção Sendas \& Veredas - CENBRA.

Foi na sala 1023 do Departamento de Filosofia da USP que, nos anos de 1990, por minha iniciativa, nasceu o GEN - Grupo de Estudos Nietzsche. Até hoje, são os mesmos princípios que o orientam: o grupo é mais do que a soma dos indivíduos que dele fazem parte; o sucesso de um de seus integrantes é o sucesso de todos; é contra o espírito de competição e a lógica da exclusão que atuamos.

I.

Sempre empenhado em formar formadores, o GEN acabou, com o passar do tempo, por produzir um "efeito multiplicador" em nosso país. Ele se faz presente em diversos Estados da Federação, do Ceará ao Rio Grande do Sul. Nos seus vinte e cinco anos de existência, não deixou de dar provas de sua vocação formadora. Seus integrantes, disseminados pelo Brasil, orientaram mais de

\footnotetext{
*Professora Titular de filosofia da USP, Brasil. Correio eletrônico: smarton@usp.br.
} 
vinte teses de doutoramento, cerca de sessenta dissertações de mestrado e por volta de noventa trabalhos de iniciação científica. Os estudantes, doutorandos, mestrandos e graduandos, que se formaram no âmbito do GEN, dedicaram-se a examinar os mais diversos temas do pensamento nietzschiano, desde as relações entre a ciência e filosofia, passando pelos problemas relativos à linguagem e ao estilo, até as questões que dizem respeito à cultura e à política.

Atualmente, o GEN reúne não só estudiosos brasileiros da filosofia nietzschiana, mas também pesquisadores europeus, constituindo um espaço de pesquisa e produção de conhecimento presente tanto em nosso território como em âmbito internacional. Atuando em três frentes distintas, o GEN organiza suas atividades em torno dos Cadernos Nietzsche, da Coleção Sendas \& Veredas e dos Encontros Nietzsche.

\section{II.}

Os Cadernos Nietzsche, que fundei em 1996, sempre tiveram, de um lado, um eixo vertical, trazendo a público textos de pesquisadores nacionais e estrangeiros experimentados, pósgraduandos e mesmo graduandos, de modo a promover o diálogo entre as gerações e, de outro, um eixo horizontal, publicando ensaios e artigos que apresentam as mais diversas vertentes interpretativas da filosofia nietzschiana.

Nossa revista trouxe ao público brasileiro, pela primeira vez em nosso país, ensaios - inéditos, muitos deles - de renomados estudiosos alemães, italianos, franceses, austríacos, espanhóis, portugueses, ingleses, norte-americanos, colombianos, venezuelanos, peruanos, uruguaios, argentinos e chilenos. Basta consultar o site www.cadernosnietzsche.unifesp.br para aquilatar a grande diversidade de estudos publicados, não só do ponto de vista da procedência de seus autores, como também da temática e 
metodologia por eles eleitas. Vale lembrar que, em versão impressa, os Cadernos Nietzsche se acham disponíveis em importantes bibliotecas, como Anna Amalia Bibliothek em Weimar, Library of Congress em Washington, Bibliothèque Nationale François Mitterand em Paris, assim como nas bibliotecas de diversas universidades da América Latina, Estados Unidos e Europa.

De início com periodicidade semestral e, mais recentemente, quadrimestral, a revista chega ao número 37 sem sofrer solução de continuidade. Graças ao empenho de Ivo da Silva Júnior, que, a partir do número 26, por ela passou a responder, foi indexada no Scielo, o que contribuiu para que viesse a ser classificada como Al pelo Qualis Periódicos da CAPES. E, graças ao trabalho de Márcio Lima, que se tornou o editor-responsável a partir do número 36, a revista continua a trazer ao público brasileiro trabalhos da mais alta qualidade, sem fazer concessões a escolas, grupos, tendências, capelas ou redes de poder.

\section{III.}

Os Encontros Nietzsche consistem num fórum permanente de debates acerca da filosofia nietzschiana. Promovidos duas vezes ao ano pelo GEN, recebem seus parceiros intelectuais tanto da cena acadêmica nacional como internacional. Ocorrendo sempre nos meses de maio e setembro, é também a ocasião em que o GEN apresenta suas publicações, lançando os novos números dos Cadernos Nietzsche e os novos títulos da Coleção Sendas \& Veredas.

$\mathrm{Na}$ medida em que os eventos destinados à divulgação dos resultados de pesquisa começaram a se multiplicar na nossa área, passamos a organizar colóquios temáticos, que privilegiam trabalhos em andamento. Neles, os participantes são convidados a porem à prova suas hipóteses interpretativas acerca de temas e problemas precisos. Exemplo disso foi a $33^{\text {a }}$ edição dos Encontros Nietzsche, que se propôs a promover o debate acerca da situação atual da 
Nietzsche Forschung. Ou então, a $34^{\mathrm{a}}$ edição, que se concentrou em discutir as "Metodologias no trato do texto nietzschiano". Sempre atento à sua vocação formadora, o GEN vem organizando, também, colóquios voltados para os jovens pesquisadores do pensamento nietzschiano entre nós.

Importa notar que, por ocasião das comemorações de seu vigésimo quinto aniversário, o GEN organizou nas duas últimas semanas de setembro o XXXVIII Encontros Nietzsche, tendo por tema "Nietzsche, pensador contemporâneo", em diversas cidades do nosso país: em Recife, na Universidade Católica de Pernambuco; em Cachoeira, na Universidade Federal do Recôncavo Baiano; em Porto Seguro, na Universidade Federal do Sul da Bahia; em Guarulhos, na Universidade Federal de São Paulo; em São Paulo, na USP; em Toledo, na Universidade do Oeste do Paraná; no Rio Grande do Sul, na Universidade Federal de Pelotas, na PUC de Porto Alegre, na Universidade de Caxias do Sul e na Universidade de Santa Maria. É uma das provas da vitalidade do nosso grupo de pesquisa.

IV.

No ano 2000, com o intuito de abrir novas frentes para os estudos sobre o pensamento nietzschiano no Brasil, criei a Coleção Sendas \& Veredas. Não há dúvida de que ela encontrou seu lugar junto à comunidade filosófica. Pretendendo ensejar novas possibilidades de reflexão, engloba três séries: "Ensaios", "Recepção" e "Fontes". A série "Ensaios" tem por propósito trazer a lume obras expressivas sobre a filosofia de Nietzsche, acolhendo trabalhos de especialistas estrangeiros de renome, estudiosos confirmados e jovens pesquisadores brasileiros. A série "Recepção" quer promover a reflexão sobre a singularidade e especificidade que marcam a leitura dos escritos nietzschianos nos mais diversos países. A série "Fontes" visa a publicar textos de pensadores com 
quem o próprio filósofo dialogou, proporcionando ferramenta de trabalho de primeira importância aos que se dedicam ao estudo das suas ideias.

Nesses dezesseis anos de existência, a Coleção Sendas \& Veredas publicou vinte e quatro títulos. O Dicionário Nietzsche, do GEN, é o mais recente. Primeira obra coletiva do nosso grupo de pesquisa, ela se destina tanto a estudiosos do pensamento nietzschiano quanto ao público em geral. Ao texto inicial que trata da vida e obra do filósofo, sucedem treze outros que apresentam cada um dos seus livros. Adotando abordagem genético-conceitual, seguem-se os 156 verbetes, todos eles assinados, que examinam conceitos centrais presentes nos escritos nietzschianos. Ao final de cada verbete, encontram-se remissões a verbetes que lhe são afins, o que permite refazer a trama conceitual presente nos textos de Nietzsche; encontram-se também remissões a passagens em que ele próprio se deteve no exame do tema tratado, o que possibilita construir o próprio itinerário no interior do livro; encontram-se ainda indicações bibliográficas precisas, o que propicia ao leitor aprofundar seus conhecimentos e sua pesquisa. Vale ainda notar que os autores se responsabilizaram pelos verbetes que estavam em consonância com a própria especialidade. Isso porque, se o GEN constitui uma experiência única de leitura e interpretação do corpus nietzschiano, também propicia a seus membros que se dediquem a diferentes aspectos dos escritos do autor de Zaratustra. Treze são os integrantes do GEN que se engajaram nessa obra pioneira na América Latina.

Recentemente, em 2015, ao GEN associou-se o CENBRA Centro de Estudos Nietzsche: Recepção no Brasil, que tem por eixo principal discutir de modo amplo a importância da presença da filosofia nietzschiana na cultura brasileira do final do século XIX 
até os nossos dias. Fundado por Ivo da Silva Júnior, o CENBRA está ligado ao Programa de Pós-graduação da UNIFESP, contando dentre as suas atividades a organização do Seminário Permanente Nietzsche no Brasil.

\section{VI.}

No que diz respeito à internacionalização do GEN, vale lembrar que, desde a sua fundação, procurei ampliar e fortalecer suas relações com importantes centros da Nietzsche Forschung, na Alemanha, na Itália, na Espanha, na França, em Portugal. Vários membros do GEN, por iniciativa minha, passaram a integrar grupos de pesquisa internacionais, como o Groupe International de Recherches sur Nietzsche (GIRN), dirigido por Giuliano Campioni, Patrick Wotling, Werner Stegmaier e eu mesma. Além de participarem de congressos europeus voltados para os estudos nietzschianos e publicarem trabalhos em revistas e livros em diversos idiomas, cultivam estreito diálogo com estudiosos estrangeiros.

Empenhando-se em consolidar parcerias intelectuais e acadêmicas, o GEN recebe pesquisadores de diversas procedências nas suas três frentes de atuação. Cadernos Nietzsche publicam textos de especialistas internacionais; os Encontros Nietzsche contam com a presença de pesquisadores estrangeiros, que vêm às próprias expensas trabalhar conosco; a Coleção Sendas \& Veredas traz à luz trabalhos seminais de estudiosos alemães, franceses, italianos, espanhóis e latino-americanos.

Acolhendo diferentes linhas interpretativas do pensamento nietzschiano, "sem desconto, exceção ou seleção", o GEN constitui um ambiente propício para a confluência e o confronto das mais diversas leituras dos escritos do filósofo, atento aos avanços realizados pela Nietzsche Forschung e às tarefas que, no momento, lhe cabem cumprir. 
O GEN se dá a conhecer através do site www.gen.fflch.usp. br, que traz informações atualizadas sobre os trabalhos de pesquisa realizados pelos seus integrantes, os títulos da Coleção Sendas \& Veredas, os Encontros Nietzsche. E põe à disposição do público, na íntegra, todos os números dos Cadernos Nietzsche. Nosso grupo de pesquisa também se comunica através da sua página https://www. facebook.com/grupodeestudosnietzsche.

Em conclusão, não seria desmedido reiterar ainda uma vez que, no decorrer dos seus vinte e cinco anos de existência, o GEN - Grupo de Estudos Nietzsche encontrou e continua a encontrar inúmeras ocasiões para confirmar a convicção de que é a diversidade que constitui a nossa maior riqueza.

\begin{abstract}
: this paper aims at taking stock of the achievements made by GEN - Nietzsche Studies Group since 1991 in Brazil and abroad.

Keywords: GEN - Cadernos Nietzsche - Encontros Nietzsche - Coleção Sendas \& Veredas - CENBRA.
\end{abstract}

Artigo recebido para publicação em 01/11/2016. Artigo aceito para publicação em 16/11/2016. 